\title{
Multi Mycotoxins Analysis in Rice Using LC-MS/MS
}

\author{
Riswahyuli', Loise RS ${ }^{1}$ and Niza Nemara ${ }^{2}$
}

${ }^{1}$ Food Safety Section, Food Division, National Quality Control of Drug and Food, Jakarta, Indonesia

${ }^{2}$ Food Division, National Quality Control of Drug and Food, National Agency of Drug and Food Control, Jakarta, Indonesia

Korespondensi: Riswahyuli

Email: yulilabiro@gmail.com

\begin{abstract}
Multi mycotoxins analysis in this research has the purpose to develop method of analysis for rice sample with a simple and fast preparation and novel technology using LC-MS/MS. Several blank rice samples were spiked with standards of 8 classes of mycotoxins (Aflatoxin B1, Aflatoxin B2, Aflatoxin G1, Aflatoxin G2, Deoxynivalenol, Zearalenon, T-2, and HT-2). Parameter of linearity, precision, recovery, limit of detection and limit of quantification were obtained and calculated. The result shows that all the validation parameters comply with criteria of method validation. Sonication method that was chosen to extract analites and Solid Phase Extraction Column that used for sample clean up are successful methods that have contribution for precise and accurate data. The Identification and quantification with LC-MS/ MS help to determine and distinguish each mycotoxin through chromatogram appearance, retention time and a specific $\mathrm{m} / \mathrm{z}$.
\end{abstract}

Keywords: multi mycotoxins; sonication; SPE; validation; LC-MS/MS 


\section{Introduction}

Mycotoxins are natural secondary metabolites produced by several species of fungi or molds on agricultural commodities in the field or during storage. Mycotoxins produced by molds because of humidity and warm temperature. This problem condition will increased by global warming issues that will change atmosfer condition to warmer temperature. Warm and humid subtropical and tropical con $\urcorner$ ditions are ideal conditions for growth and colo $\neg$ nisation of several mycotoxins producers. The other condition favoring the mycotoxins production is storage contaminated foodstuffs under damp conditions [1, 2]. Mycotoxins have severe toxic effect to human and animals because of several symptoms result after consuming food by toxins. The main toxic effects are carcinogenicity, genotoxicity, nephrotoxicity, hepatotoxicity, oestrogenicity, reproductive disorders, immunosuppression or dermal effects. Several mycotoxins have been found in rice. Rice (Oryza sativa L.) is the most important staple food crop in Asia, especially in Indonesia. Based on data from Statistic Division Food and Agriculture Organization of the United Nations (2014), Indonesia is the third largest country regarding rice production. On the contrary, it is still rice importer because of large consumtion (Sources: Food and Agriculture Organization of the United Nations and Indonesian Ministry of Agriculture). Rice cultivation is well-suited to tropical regions that have a warm climate and high amounts of rainfall because requires high water supply. There are several mycotoxins which have been found in rice. They are produced majority by Aspergillus sp. [3], Fusarium sp. [4] and Penicillium sp. [5].

Since 1961, there have been several methods used for mycotoxins analysis. The famous method is HPLC analysis, because of its sensitivity and selectivity. However the most recent method using LC-MS/MS was found and will provide a better method since it has better resolution and selectivity [6]. In LC-MS/MS it is possible to us to de- termine multi analysis rather than single analysis in HPLC.

Furthermore, there are many different ways of sample preparation for mycotoxins analysis, but only a little can be done for multi components in a simple way. Preparation method for multi toxin was done using organic solvent without clean-up process $[7,8]$ but ion-suppression effects due to co-eluting matrix components were leading to purely proportional systematic errors, therefore a new simply method need to be developed. This research was designed to develop a preparation method using sonication, clean up through SPE and developed a method validation for multi mycotoxins in rice simutaneously using LC-MS/MS.

\section{Methods}

\subsection{Chemicals and materials}

Mycotoxin standards AFB1, AFB2, AFG1, AFG2, DON, ZON,T-2 and HT-2 were obtained from Trilogy ${ }^{\circledR}$ R-Biopharm. Ultrapure deionized water of $18.2 \mathrm{M} \Omega . \mathrm{cm}$ resistivity was produced from a water purification system, HPLC grade acetonitrile (ACN) and methanol $(\mathrm{MeOH})$, formic acid and ammonium acetate were obtained from Merck $^{\circledR}$ (Germany). HPLC Column XTerra ${ }^{\circledR}$ MS C18, $100 \mathrm{~mm} \times 2,1 \mathrm{~mm}$ ID, 3,5 $\mu \mathrm{m}$ particle size; blender; sonicator Branson 2510; SPE Mycosep ${ }^{\circledR}$ 226; erlenmeyer $250 \mathrm{ml}$; micropipette 1-20 $\mu \mathrm{l}$, 20-200 $\mu \mathrm{l}, 100-1000 \mu \mathrm{l}$, and LC-MS/MS Waters Acquity system.

\subsection{Standards solution}

Working standard solution was prepared by mixing single standard of mycotoxins to obtain concentration of Aflatoxin B1, Aflatoxin B2, Aflatoxin G1, and Aflatoxin G2 $(0.1 ; 0.2 ; 0.8 ; 3.1 \mathrm{ng} /$ $\mathrm{ml})$, Deoxinivalenol/DON (25; 100; 200; $500 \mathrm{ng} /$ $\mathrm{ml}$ ), HT-2, T-2, and Zearalenon (5; 20; 40; $100 \mathrm{ng} /$ $\mathrm{ml}$ ) with metanol:water (1:1).

\subsection{Sample preparation}

Rice samples from Indonesia market (pandan wangi rice) were crushed and blended. Finely 
ground sample were weighed about $25 \mathrm{~g}$ in erlenmeyer $250 \mathrm{ml}$, spiked with $3 \mathrm{ml}$ stock standar DON $(2000 \mu \mathrm{g} / \mathrm{ml}), \mathrm{HT}-2(400 \mu \mathrm{g} / \mathrm{ml})$, T2 (400 $\mu \mathrm{g} / \mathrm{ml})$ and $\mathrm{ZON}(400 \mu \mathrm{g} / \mathrm{ml})$ and $0.3 \mathrm{ml}$ intermediate standard of Aflatoxin ( $80 \mathrm{ng} / \mathrm{ml})$, allowed to stand for at least 30 minutes to allow the solvent to evaporate off. Add $100 \mathrm{ml}$ acetonitrile : water (84:16) and extract by ultrasounds for $10 \mathrm{~min}$ at $50^{\circ} \mathrm{C}$. Filter the mixture sample through filter paper $[9,10]$.

\subsection{Clean up}

Filtered supernatan $(8 \mathrm{ml})$ were transfered to the glass tube, acidified with $80 \mu \mathrm{l}$ acetic acid, transfered to the glass tube and pussed all through SPE Mycosep column until we got $4 \mathrm{ml}$ clean extract. One $\mathrm{ml}$ extract was transfered to vial, evaporated until dryness and redisolved with methanol:water (30:70) (Figure 1).

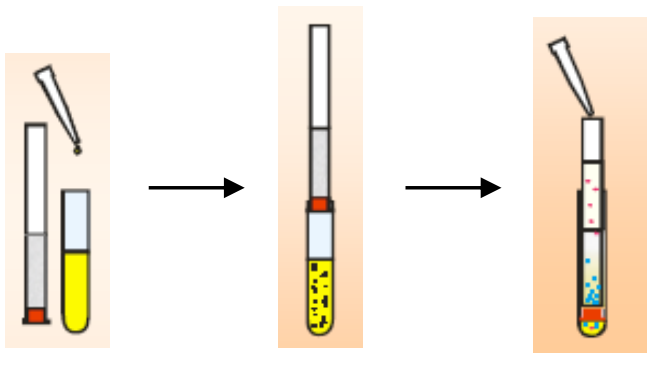

Figure 1. Clean up process with Mycosep (Multi Sep ${ }^{\circledR}$ Working Principle, Romer Labs)

\subsection{LC-MS/MS condition}

Detection and quantification were performed using Liquid Chromatography coupled to a triplequadrupole mass spectrometry (Waters Alliance 2695 Quatro Premiere) and set to condition: mobile phase with gradient concentration (Table 1), column XTerra ${ }^{\circledR}$ MS C18 $100 \mathrm{~mm}$ x 2,1 mm ID, particle size $5 \mu \mathrm{m}$, flow rate $0.3 \mathrm{ml} / \mathrm{min}$, injection volume $50 \mu$ l. Acquisition simultaneously acquired with MRM (multiple reaction monitoring) transition (Table 2).
Table 1. Chromatographic gradient condition

\begin{tabular}{lll}
\hline $\begin{array}{l}\text { Time } \\
(\mathbf{m i n})\end{array}$ & $\begin{array}{l}\text { Water } \\
(\mathbf{\%})\end{array}$ & $\begin{array}{l}\text { Methanol } \\
(\mathbf{\%})\end{array}$ \\
\hline 0 & 70 & 30 \\
5 & 0 & 100 \\
5.01 & 70 & 30 \\
10 & 70 & 30 \\
\hline
\end{tabular}

\section{Results and discussion}

Method validation for determination multi mycotoxins in rice flour has been done in 3 steps: sample preparation, instrument measurement, and data analysis.

\subsection{Sample Preparation}

Sample preparation consists of 4 steps: sample homogenization, sub-sampling, sample extraction, and clean up process. Sample homogenization was done by crushing and blending rice into fine ground flour with blender and homogenizer. This step is important to make easier accessibility to solvent to extract the analytes from rice matrices by opening and obtaining wider surface area of samples.

After homogenizing, to ensure measurement of representative samples, the sub-sampling was done by separating about $10 \mathrm{~kg}$ rice flour samples into 6-8 groups in to quadrant and mixed them to two groups. Finally mixed all groups and weighed sample randomly. Homogenization and subsampling is important typical step that should be done because non uniformly distribution of mycotoxins in matrices. Non representative samples imply wrong interpretation during data analysis. Extraction step is a critical step after sub sampling and weighing. A successful extraction process will obtain an accurate result. Therefore, an optimized extraction procedure need to be chosen to provide result complying the validation requirements. In this research, a relatively simple extraction was used by diluted sample with organic solvent and sonicate the mixture at $50^{\circ} \mathrm{C}$ for 10 minutes. The sonication method was developed 
Table 2. MRM parameters

\begin{tabular}{|c|c|c|c|c|c|}
\hline & $\begin{array}{l}\text { Precursor } \\
\text { ion }\end{array}$ & $\begin{array}{l}\text { Cone } \\
\text { (V) }\end{array}$ & $\begin{array}{l}\text { Product } \\
\text { ion }\end{array}$ & $\begin{array}{l}\text { Collision } \\
\text { energy (V) }\end{array}$ & $\begin{array}{l}\text { Ionization } \\
\text { mode }\end{array}$ \\
\hline AFB1 & 313.2 & 45 & $\begin{array}{l}241.2^{*} \\
285.2^{* *}\end{array}$ & $\begin{array}{l}40 \\
22\end{array}$ & ES + \\
\hline AFB2 & 315.2 & 45 & $\begin{array}{l}259.2^{*} \\
287.2^{* *}\end{array}$ & $\begin{array}{l}30 \\
25\end{array}$ & ES + \\
\hline AFG1 & 329.2 & 17 & $\begin{array}{l}283.2^{*} \\
243.2^{* *}\end{array}$ & $\begin{array}{l}27 \\
25\end{array}$ & ES + \\
\hline AFG2 & 331.30 & 45 & $\begin{array}{l}245.3^{*} \\
257.2^{* *}\end{array}$ & $\begin{array}{l}30 \\
30\end{array}$ & ES + \\
\hline DON & 295.1 & 25 & $\begin{array}{l}265.1^{*} \\
137.9^{* *}\end{array}$ & $\begin{array}{l}12 \\
15\end{array}$ & ES - \\
\hline $\mathrm{T}-2$ & 489.0 & 55 & $\begin{array}{l}245.0^{*} \\
387.1^{* *}\end{array}$ & $\begin{array}{l}28 \\
23\end{array}$ & ES + \\
\hline HT-2 & 447.1 & 70 & $\begin{array}{l}345.1^{*} \\
285.1^{* *}\end{array}$ & $\begin{array}{l}20 \\
20\end{array}$ & ES + \\
\hline ZON & 317.2 & 40 & $\begin{array}{l}174.9^{*} \\
148.9^{* *}\end{array}$ & $\begin{array}{l}24 \\
22\end{array}$ & ES - \\
\hline
\end{tabular}

* : quantifier ion $\quad$ ES + : Electrospray positive ionization

** : qualifier ion ES - : Electrospray negative ionization

by AETS in Europe as an innovation extraction method in mycotoxins that substitute a regular method using high speed blender or shaker. This method have simple handle and allows an effective and intensive solvent-matrices interaction. After extraction step, due to the complexity of samples, clean up process is needed. SPE columns that contains a combination of adsorbents were used. The procedur of clean up in this method is very easy. We just push all the mixture through the column and take a portion of filtrat and evaporate them to concetrated solution that ready to be analyzed in LC-MS/MS system.

\subsection{LC-MS/MS analysis}

A simultaneous analysis is complex analysis. Sometimes 2 analytes can not be measured in one type of detector and column in LC system because of limitation the system to separate them. Both analytes can not be detected separately because of simililarity in their structure. We need another detector that have more ability and sufficient to separate and detect more than one analyte in a time. Mass Spectrometry is detector that have ability to separate one to another analyte by ion characterization $(\mathrm{m} / \mathrm{z})$. The system can break the molecule and make ionization, change molecul to ion form with spesific m/z. By Multiple Reaction Monitoring (MRM), the system can be set up to detect analyte from their spesific ion $(\mathrm{m} / \mathrm{z})$ and made a possibility for us to separate and detected 8 classes of mycotoxins.

Some of them had same retention time, example in Aflatoxin B1 and Aflatoxin B2 but that not important anymore, because we can distinguished the analyte by $\mathrm{m} / \mathrm{z}$. Figure 2 shows a cromatograms of targeted ions from 8 classes mycotoxins. They could analyzed simultaneously without any interfere one each other.

\subsection{Validation}

Validation definition by International Organization for Standarization [11], is the confirmation by examination and the provision of objective evidence that the particular requirements for a specific intended use are fulfilled. A "single-laboratory method validation" was chosen to this study because it is not always practical or necessary to provide full validation of analytical methods in several circumstances such as unavailable collaborative laboratories [12]. Linearity were evaluated by calibration curve that were build by analyzing spiked matrices with serial mycotoxins standard. 

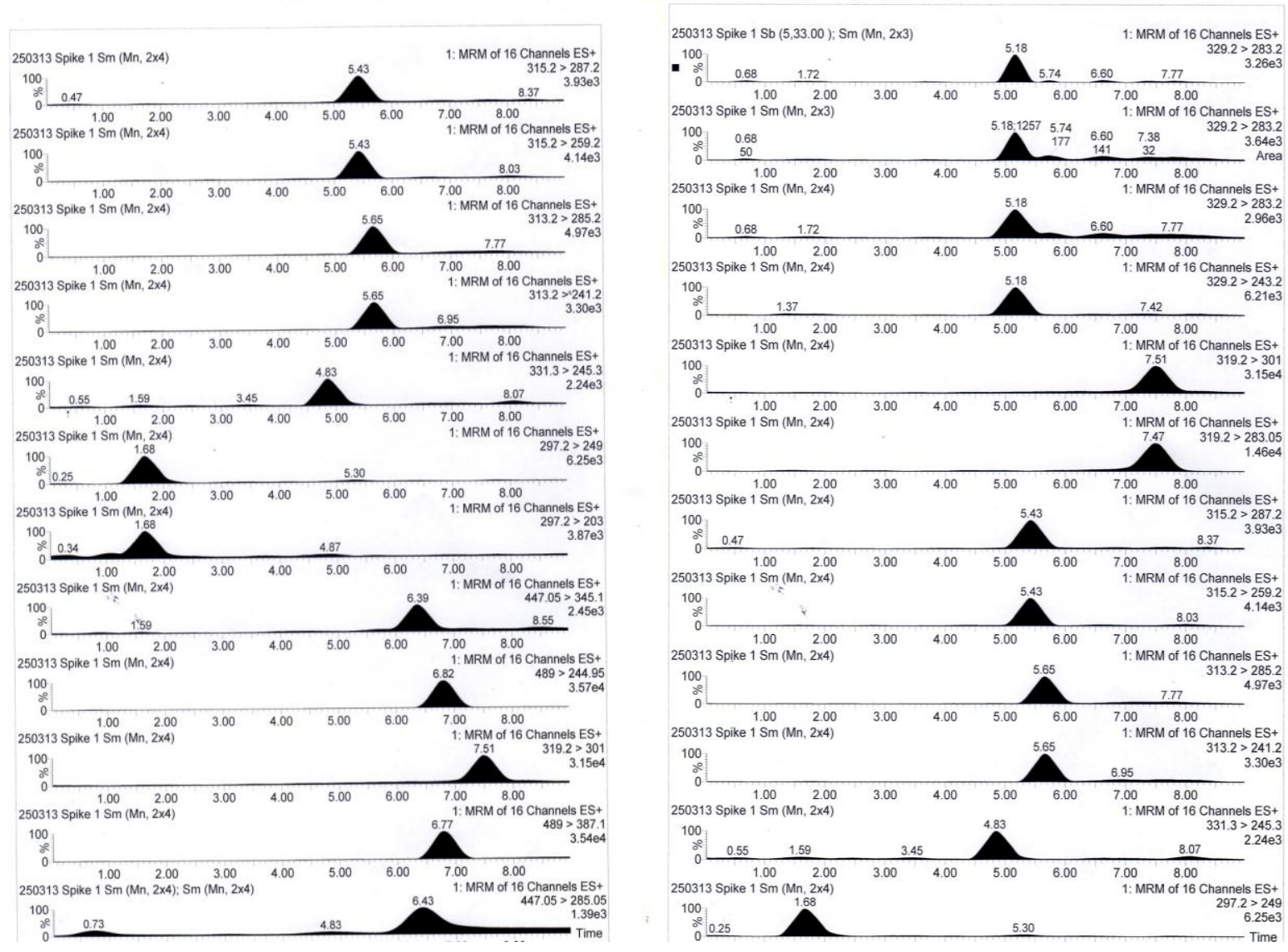

Figure 2. Chromatograms of Product Ionization of AFB1 (313.2 $>241.2,313.2>285.2)$, AFB2 (312.2>259.2, 315.2>287.2), AFG1 (329.2>283.2, 329.2>243.2), AFG2 $(331.3>245.3,331.3>257.2)$, DON (295.1>265.1, 295.1>137.9), T-2 (489.0>245.0, 489.0>387.1), HT-2 (447.1>345.1, 447.1>285.1) and ZON (317.2>174.9, 317.2>148.9)

Table 3. Linearity of calibration curve of standard mycotoxins

\begin{tabular}{llllll}
\hline Mycotoxins & Slope (b) & Intercept (a) & $\mathbf{r}$ & Criteria & $\begin{array}{l}\text { Complying to } \\
\text { Criteria (Yes/No) }\end{array}$ \\
\hline AFB1 & 1833.57 & -49.5769 & 0.9987 & $>0,99$ & Yes \\
AFB2 & 2480.37 & -75.662 & 0.9996 & & Yes \\
AFG1 & 2147.45 & 81.2484 & 0.9997 & & Yes \\
AFG2 & 1286.08 & -9.20477 & 0.9999 & Yes \\
DON & 21.7004 & 25.2751 & 0.9980 & Yes \\
HT-2 & 118.316 & -300.934 & 0.9942 & Yes \\
T-2 & 1513.35 & 1030.58 & 0.9993 & & Yes \\
ZON & 1321.33 & -4587.93 & 0.9966 & & Yes \\
\hline
\end{tabular}

The results (Table 3) showed that all mycotoxins have external calibration linearity above 0.99 and were comply to that criteria. In analytical practice, calibration graph frequently give nu- merical $r$-value greater than 0.99 , and $r$-value less than about 0.90 are relatively uncommon and the best straight line if $r$-value is very close to 1 [13]. Precision were analyzed by calculating RSD 
Table 4. Precision of mycotoxins

\begin{tabular}{llllll}
\hline Mycotoxins & $\begin{array}{l}\text { Concentration } \\
(\boldsymbol{\mu g} / \mathbf{k g})\end{array}$ & RSD (\%) & $\begin{array}{l}\mathbf{2 / 3} \mathbf{~ C V} \\
\text { Horwitz (\%) }\end{array}$ & Criteria & $\begin{array}{l}\text { Complying to } \\
\text { Criteria (Yes/No) }\end{array}$ \\
\hline AFB1 & 4.05 & 11.86 & 14.64 & $<2 / 3$ CV Horwitz & Yes \\
AFB2 & 3.78 & 5.02 & 14.64 & & Yes \\
AFG1 & 4.05 & 5.41 & 14.64 & Yes \\
AFG2 & 3.27 & 12.37 & 14.64 & Yes \\
DON & 218.45 & 11.74 & 14.64 & Yes \\
HT-2 & 47.78 & 1.94 & 10.67 & Yes \\
T-2 & 40.61 & 3.25 & 10.67 & Yes \\
ZON & 45.66 & 7.14 & 10.67 & Yes \\
\hline
\end{tabular}

Table 5. Recovery of mycotoxins

\begin{tabular}{llll}
\hline Mycotoxin & Recovery Range (\%) & N & Criteria \\
\hline AFB1 & $77.30-106.40$ & 5 & \\
AFB2 & $67.38-95.09$ & 6 & \\
AFG1 & $86.92-103.01$ & 4 & \\
AFG2 & $71.29-94.26$ & 6 & \\
DON & $77.61-103.27$ & 5 & \\
HT-2 & $96.70-102.12$ & 6 & \\
T-2 & $99.54-100.37$ & 6 & \\
ZON & $87.19-105.53$ & 5 & \\
\hline
\end{tabular}

concentration of repeated samples. Rice samples in this study are not contain of mycotoxins. We should spiked samples with mycotoxins and analyzed time with $n=6$. We got result RSD for all types of mycotoxins below 2/3 CV Horwitz (Table 4 ), so that the method is precise and can be use in the future $[14,15,16]$.

Recovery of mycotoxins were analyzed to evaluate mainly in preparation or extraction process. The method would have good recovery if all analyte can be extracted and calculated from the sample matrices. In this method, recovery were relative fluctuative depending the type of mycotoxins but generally still in range $60-115 \%$ (Table 5).

LOD and LOQ were calculated to measure the sensitivity of the method. Limit of Detection mycotoxins for this method were obtain in 0.08-3.34 $\mu \mathrm{g} / \mathrm{kg}$ and can be quantified from range level
0.21-11.13 $\mu \mathrm{g} / \mathrm{kg}$ (Table 6). This level still below limit concentration of mycotoxins based on Indonesian or most the strict regulation in the world, European regulation that have range from 4-8 $\mathrm{mg} / \mathrm{kg}[17,18]$.

Table 6. Limit detection and limit quantitation

\begin{tabular}{lll}
\hline Mycotoxins & LOD $(\mu \mathrm{g} / \mathrm{kg})$ & LOQ $(\mu \mathrm{g} / \mathrm{kg})$ \\
\hline AFB1 & 0.08 & 0.27 \\
AFB2 & 0.20 & 0.67 \\
AFG1 & 0.14 & 0.46 \\
AFG2 & 0.06 & 0.21 \\
DON & 3.34 & 11.13 \\
HT-2 & 0.93 & 3.10 \\
T-2 & 0.21 & 0.68 \\
ZON & 0.19 & 0.62 \\
\hline
\end{tabular}




\section{Conclusion}

Method of validation multi mycotoxins in rice by LC-MS/MS was developed and has been complied with validation criteria. The method can be used to determine 8 classes mycotoxins (Aflatoxin B1, Aflatoxin B2, Aflatoxin G1, Aflatoxin G2, Deoxynivalenol, Zearalenon, T-2, and HT-2) in rice comoditi. Multi mycotoxins analysis using LCMS/MS is simultaneous method that have high selectivity and sensitivity to confirm and quantify the concentration of mycotoxins.

\section{Acknowledgement}

The results presented here are the part of project method validation supported by National Quality Control Laboratory for Drug and Food, National Agency for Drug and Food Control, Republic Indonesia and European Trade Support Program.

\section{References}

1. Peraica M, Radic B, Lucic A, Pavlovic M. Toxic effects of mycotoxins in humans. Bulletin of the World Health Organization. 1999;77(9):754-66.

2. Milani JM. Ecological conditions affecting mycotoxin production in cereals: a review. Veterinarni Medicina. 2013;58(8):405-11.

3. Reddy CS, Reddy KR, Kumar RN, Laha GS, Muralidharan K. Exploration of aflatoxin contamination and its management in rice. Journal of Mycology and Plant Pathology. 2004;34(3):816-20.

4. Abbas HK, Cartwright RD, Xie W, Mirocha CJ, Richard JL, Dvorak TJ, Sciumbato GL, Shier WT. Mycotoxin production by Fusarium proliferatum isolates from rice with Fusarium sheath rot disease. Mycopathologia. 1999;147(2):97-104.

5. Makun HA, Gbodi TA, Akanya OH, Salako EA, Ogba$\mathrm{du}$ GH. Fungi and some mycotoxins contaminating rice (Oryza sativa) in Niger state, Nigeria. African Journal of Biotechnology. 2007;6(2).

6. Berthiller F, Sulyok M, Krska R, Schuhmacher R.
Chromatographic methods for the simultaneous determination of mycotoxins and their conjugates in cereals. International Journal of Food Microbiology. 2007;119(1):33-7.

7. Delmulle B, De Saeger S, Adams A, De Kimpe N, Van Peteghem C. Development of a liquid chromatography/tandem mass spectrometry method for the simultaneous determination of 16 mycotoxins on cellulose filters and in fungal cultures. Rapid communications in mass spectrometry. 2006;20(5):771-6.

8. Sulyok M, Berthiller F, Krska R, Schuhmacher R. Development and validation of a liquid chromatography/tandem mass spectrometric method for the determination of 39 mycotoxins in wheat and maize. Rapid communications in mass spectrometry. 2006;20(18):2649-59.

9. Organization of Training Courses on Food Testing. AETS Consortium. European Method Contract No. 201196 06. Organisation and Implementation of Training Activities on Sampling and Analysis Methods Used in the Context of Official Food and Feed Control. www.foodinfo-europe.com

10. Pusat Pengujian Obat dan Makanan Nasional (PPOMN) in house method. 2013. Validasi metode penetapan kadar Aflatoksin B1, Aflatoksin B2, Aflatoksin G1, Aflatoksin G2, Deoksinivalenol, HT-2, T-2 dan Zearalenon pada produk-produk serealia. 13/PA.13

11. International Organization for Standarization, ISO/IEC 17025. General requirements for the competence of testing and calibration laboratories, Geneva; 2005.

12. Thompson M, Ellison SL, Wood R. Harmonized guidelines for single-laboratory validation of methods of analysis (IUPAC Technical Report). Pure and Applied Chemistry. 2002;74(5):835-55.

13. Miller JN, Miller JC. Statistics and chemometrics for analytical chemistry. Harlow: Pearson Education; 2005.

14. Horwitz W, Albert R. The Horwitz ratio (HorRat): a useful index of method performance with respect to precision. Journal of AOAC International. 2006;89(4):1095-109.

15. Horwitz W. AOAC guidelines for single laboratory 
validation of chemical methods for dietary supplements and botanicals. AOAC International, Gaithersburg, MD, USA; 2002.

16. Alimentarius C. Guidelines for the design and implementation of national regulatory food safety assurance programme associated with the use of veterinary drugs in food producing animals. CAC/
GL, 71-2009; 2014.

17. No EC. Setting maximum levels for certain contaminants in foodstuffs. Official Journal of the European Union L. 2006;364(5).

18. Commission Recommendation 2013/165/EU on the presence of T-2 and HT-2 toxin in cereals and cereal products. 